\title{
Pre-oxidation and its effect on reducing high-temperature corrosion of superheater tubes during biomass firing
}

Okoro, Sunday Chukwudi; Kvisgaard, M.; Montgomery, Melanie; Jappe Frandsen, Flemming; Pantleon, Karen

Published in:

Surface Engineering

Link to article, DOI:

10.1080/02670844.2016.1199128

Publication date:

2017

Document Version

Peer reviewed version

Link back to DTU Orbit

Citation (APA):

Okoro, S. C., Kvisgaard, M., Montgomery, M., Jappe Frandsen, F., \& Pantleon, K. (2017). Pre-oxidation and its effect on reducing high-temperature corrosion of superheater tubes during biomass firing. Surface Engineering, 33(6), 428-432. https://doi.org/10.1080/02670844.2016.1199128

\section{General rights}

Copyright and moral rights for the publications made accessible in the public portal are retained by the authors and/or other copyright owners and it is a condition of accessing publications that users recognise and abide by the legal requirements associated with these rights.

- Users may download and print one copy of any publication from the public portal for the purpose of private study or research.

- You may not further distribute the material or use it for any profit-making activity or commercial gain

- You may freely distribute the URL identifying the publication in the public portal 


\title{
Pre-oxidation and its effect on reducing high temperature corrosion of superheater tubes during biomass
}

\section{firing*}

Sunday Chukwudi Okoro ${ }^{1 a}$, Magnus Kvisgaard ${ }^{1}$, Melanie Montgomery ${ }^{1}$, Flemming Jappe Frandsen², Karen Pantleon $^{1}$

${ }^{1}$ Technical University of Denmark (DTU), Department of Mechanical Engineering, building 425, 2800 Kongens Lyngby, Denmark ( ${ }^{a}$ sunoko@mek.dtu.dk)

${ }^{2}$ DTU, Department of Chemical and Biochemical Engineering, building 228, 2800 Kongens Lyngby, Denmark

*Paper presented during the session on high temperature corrosion

\begin{abstract}
Superheater tubes in biomass-fired power plants experience high corrosion rates due to condensation of corrosive alkali chloride rich deposits. To explore the possibility of reducing the corrosion attack by the formation of an initial protective oxide layer, the corrosion resistance of pre-oxidized Al and Ti-containing alloys (Kanthal APM and Nimonic 80A, respectively) was investigated under laboratory conditions mimicking biomass-firing. The alloys were pre-oxidized at $900{ }^{\circ} \mathrm{C}$ for 1 week. Afterwards, pre-oxidized samples, and virgin non-pre-oxidized samples as reference, were coated with a synthetic deposit of $\mathrm{KCl}$ and exposed at $560{ }^{\circ} \mathrm{C}$ for 1 week to a gas mixture typical of biomass firing. Results show that pre-oxidation could hinder the corrosion attack; however the relative success was different for the two alloys. While corrosion attack was observed on the preoxidized Kanthal APM, the morphology of the preoxidized Nimonic 80A was significantly unaffected suggesting protection of the alloy from the corrosive environment.
\end{abstract}




\subsection{Introduction}

Material selection for applications in biomass fired power plants is quite challenging due to the corrosive nature of such environments. ${ }^{1}$ During combustion of biomass in thermal power plants, alkali chloride-rich deposits condense on the surface of superheater tubes thereby causing corrosion of the materials. The high corrosion rate imposes a limit to the maximum operating steam temperatures of thermal power plants firing biomass. Consequently, efficiency is limited.

Material degradation under biomass-firing conditions is due to the reaction with both the alkali metal and chlorine present in condensed deposits. ${ }^{2}$ In addition, the reactions between superheater materials and the corrosive species present in the flue gas often results in high degradation rates. A combination of these parameters results in rather complex corrosion phenomena under biomass-firing conditions. Extensive studies ${ }^{3}$ have shown that the alkali metal present in the deposit can react with the native chromium oxide $\left(\mathrm{Cr}_{2} \mathrm{O}_{3}\right)$ formed on austenitic stainless steels as follows:

$$
\mathrm{KCl}(\mathrm{s})+\frac{1}{4} \mathrm{Cr}_{2} \mathrm{O}_{3}(\mathrm{~s})+\frac{3}{8} \mathrm{O}_{2}(\mathrm{~g})+\frac{1}{2} \mathrm{H}_{2} \mathrm{O}(\mathrm{g}) \rightleftharpoons \frac{1}{2} \mathrm{~K}_{2} \mathrm{CrO}_{4}(\mathrm{~s})+\mathrm{HCl}(\mathrm{g})
$$

The consumption of $\mathrm{Cr}$ by this reaction prevents the formation of the protective $\mathrm{Cr}_{2} \mathrm{O}_{3}$ and releases $\mathrm{HCl}$. As a result, a fast growing porous Fe-rich oxide forms on the surface of the alloy. Such oxide allows the transport of chlorine which propagates corrosion attack by a chlorination-oxidation mechanism ${ }^{2,4}$.

To achieve higher steam temperatures (and plant efficiency), materials for superheater tubes in biomass-fired power plants will have to exhibit resistance to attack by both the corrosive deposit and the flue gas species. This implies that in addition to the basic requirement of slow creep and good steam oxidation resistance at high temperatures, these materials should have surface properties that inhibit fireside corrosion where corrosive species such as $\mathrm{KCl}, \mathrm{K}_{2} \mathrm{CO}_{3}, \mathrm{~K}_{2} \mathrm{SO}_{4}, \mathrm{HCl}, \mathrm{SO}_{2}$, etc. are present. In line with this, recent investigations have addressed the performance of preformed oxides ${ }^{5,6,7,8}$ as well as coatings ${ }^{9,10}$ on some commercial alloys as a way to improve 
their corrosion resistance. Some of these investigations provide indications of the ability of the preformed oxides or coatings to delay the onset of corrosion attack by the corrosive $\mathrm{KCl}$ deposit.

The present study focuses on the effect of pre-oxidation to form protective oxides in order to prevent the corrosion attack under well controlled laboratory conditions mimicking biomass-firing. A recent study on the reactivity of some oxides with $\mathrm{KCl}$ indicated no significant reaction between $\mathrm{KCl}$ and the oxides $\mathrm{Al}_{2} \mathrm{O}_{3}$ and $\mathrm{TiO}_{2} \cdot{ }^{11}$ On the basis of this result, the present investigation studied the corrosion protection of preformed oxides on two commercial alloys (Kanthal APM and Nimonic 80A) containing $\mathrm{Al}$ or Ti as alloying elements in addition to Cr.

\subsection{Methods}

The commercial alloys investigated in this study were a FeCrAl alloy (Kanthal APM) and a Ni-based superalloy (Nimonic 80A) with chemical compositions given in Table 1. Samples were cut from tubes and were degreased in acetone and dried in ethanol prior to initial oxidation or corrosion exposure.

Pre-oxidation of the samples was carried out in a horizontal furnace at $900{ }^{\circ} \mathrm{C}$ under a flow of pure oxygen for the period of $168 \mathrm{~h}$. Morphological characterization of the resulting oxides was carried out by scanning electron microscopy (SEM) using a FEI Inspect S microscope. An energy dispersive spectrometer (EDS) attached to the SEM was employed for quantification of the chemical composition. Qualitative phase analysis was carried out by X-ray diffraction (XRD) in grazing incidence geometry using a D8 Discover diffractometer from Bruker AXS equipped with $\mathrm{Cr}-\mathrm{K} \alpha$ radiation.

The corrosion performance of the pre-oxidized samples was evaluated after laboratory exposures to conditions mimicking biomass firing in thermal power plants. To facilitate this, the samples were coated with a slurry of synthetic deposit consisting of $\mathrm{KCl}$. As a reference, virgin samples of each alloy without any pre-oxidation were coated with the same deposit and exposed to identical corrosive conditions. The corrosion exposures were performed in a dedicated laboratory test rig that allowed mimicking deposit-induced corrosion as experienced in power plants. The corrosion test rig consists of an electrically heated furnace, a gas mixing panel and a cleaning 
system for the flue gas, a detailed description of the test rig is given elsewhere. ${ }^{12}$ The composition of the gas atmosphere used in the present exposures is given in Table 2.

Mass flow controllers in the gas mixing panel were used to obtain the desired concentration of the gas components in the final gas stream. The corrosion exposure of both pre-oxidized and virgin samples was carried out at $560{ }^{\circ} \mathrm{C}$ for 168 h. This temperature was chosen to reproduce the metal temperature experienced by actual superheater tubes operating in power plant with a steam temperature of $540{ }^{\circ} \mathrm{C}$. The corrosion attack of samples with and without pre-oxidation was evaluated by characterization of the corrosion products using scanning electron microscopy (SEM), energy dispersive spectroscopy (EDS), and X-ray diffraction (XRD) techniques.

\subsection{Results}

3.1 Oxide morphologies and chemical composition after pre-oxidation

The surface topography and morphology of oxides resulting from pre-oxidation of the investigated alloys at $900{ }^{\circ} \mathrm{C}$ for $168 \mathrm{~h}$ is shown in Figure 1.

The oxide on Kanthal APM formed a blade-like morphology whereas the oxide on Nimonic 80A showed features with both globular and faceted morphologies. EDS analysis indicated that Al-rich oxides formed on Kanthal APM. Cross section analysis showed that the Al-rich oxide was about $500 \mathrm{~nm}$ thick. Grazing incidence XRD revealed the presence of both $\alpha-\mathrm{Al}_{2} \mathrm{O}_{3}$ and $\mathrm{Cr}_{2} \mathrm{O}_{3}$ on pre-oxidized Kanthal APM. Interestingly, the phase $\left(\mathrm{Al}_{0.94} \mathrm{Cr}_{0.052}\right)_{2} \mathrm{O}_{3}$ was also identified in the recorded diffractogram suggesting the possibility of a solid solution of the oxides.

On the other hand, on the surface of pre-oxidized Nimonic 80A, a Cr-Ti-rich oxide was identified. Cross section analysis of pre-oxidized Nimonic 80A revealed an about $8 \mu \mathrm{m}$ thick outer oxide (with Ti and Cr enrichment in the near surface region), and an about $14 \mu \mathrm{m}$ thick $\mathrm{Al}$ and Ti-rich inner oxide layer with a needle-like morphology In addition, an internal oxidation zone was present along the grain boundaries. With grazing incidence $\mathrm{XRD} \mathrm{TiO}_{2}$ and $\mathrm{Cr}_{2} \mathrm{O}_{3}$ were both identified in addition to the phase $\left(\mathrm{Cr}_{0.88} \mathrm{Ti}_{0.12}\right)_{2} \mathrm{O}_{3}$. 
3.2 Corrosion performance of pre-oxidized samples under biomass firing conditions

Figure 2 presents the morphology and composition of corrosion products formed on a pre-oxidized Kanthal APM sample after exposure to conditions mimicking biomass-firing. The preformed oxide was not able to protect the alloy from corrosion attack as the EDS maps reveal that $\mathrm{Fe}, \mathrm{Cr}$ and $\mathrm{Al}$ were all removed from the alloy bulk and embedded in a porous corrosion product on the surface. The interaction between the deposit particles $(\mathrm{KCl})$ and the flue gas resulted in the formation of sulphate containing compounds in the deposit. ${ }^{12}$ Similarly, the virgin Kanthal APM alloy also suffered severe corrosion attack as revealed in Figure 3. The chemical composition of the corrosion products formed on Kanthal APM samples was similar irrespective of the applied pre-oxidation.

In contrast, no observable form of degradation was observed after exposure of pre-oxidized Nimonic 80A samples to the corrosive atmosphere (Figure 4). The chemical composition of the preformed oxide remained unchanged, but in addition, a sulphate layer had formed above this oxide due to the reaction of the deposit with $\mathrm{SO}_{2}$ in the atmosphere during exposure. ${ }^{12}$ However, the virgin Nimonic 80A suffered from corrosion attack after the exposure (Figure 5). The corrosion attack caused the removal of $\mathrm{Ni}, \mathrm{Cr}, \mathrm{Al}$ and $\mathrm{Ti}$ from the alloy and their redeposition on top of the alloy as a porous and heterogeneous layer.

\subsection{Discussion}

$\mathrm{Al}_{2} \mathrm{O}_{3}$ scales are known to be protective under oxidizing conditions, because they can maintain low corrosion rates of the underlying bulk materials. However, the results observed in the current study suggest that the presence of corrosive species such as $\mathrm{KCl}$ and $\mathrm{SO}_{2}$ causes breakdown of the oxide scale. As a result, severe corrosion of the Kanthal APM alloy occurred. The mechanism of such fast corrosion is suggested to follow chlorination of the alloying elements such as $\mathrm{Cr}$, Fe and Al, leading to the formation of volatile metal chlorides. The ability of these species to be transported as gaseous species reduces the chance of protective layer formation due to the porous nature of the oxides. 
The Ti-Cr-rich oxide formed on Nimonic 80A showed good protection against corrosion attack. This is attributed to the less favourable interaction between $\mathrm{TiO}_{2}$ in the oxide and $\mathrm{KCl}$ during the initial stages of corrosion. Thermodynamic studies related to such interactions have been reported in literature. ${ }^{11}$ As a result, breakdown of the oxide did not proceed during exposure of pre-oxidized Nimonic 80A to biomass firing conditions.

\subsection{Summary}

The effect of chemical modifications by pre-oxidizing the surfaces of two commercial alloys (Kanthal APM and Nimonic 80A) on their corrosion resistance under laboratory conditions mimicking biomass firing in thermal power plants was evaluated. Pre-oxidation caused the formation of different oxide scales on both alloys. The TiCr-rich oxide formed on Nimonic 80A considerably reduced the corrosion attack compared to the virgin Nimonic 80A, whereas the Al-rich oxide on Kanthal APM was unable to protect the alloy from corrosion under biomass firing conditions. The different performance of both alloys after pre-oxidation is explained in relation to the reactivity between the oxides and the corrosive environment.

\subsection{Acknowledgements}

This work is part of the Danish Strategic Research Centre, Power Generation from Renewable Energy (GREEN). Funding from the Danish council for Strategic Research is acknowledged by the authors.

\subsection{References}

1. F. J. Frandsen: Ash formation, deposition and corrosion when utilizing straw for heat and power production, ISBN: 9788792481405, Department of Chemical and Biochemical Engineering, Technical Univeristy of Denmark, Kgs. Lyngby, 2011. 
2. S. C. Okoro, M. Montgomery, F.J. Frandsen, K. Pantleon: 'High temperature corrosion under laboratory conditions simulating biomass-firing: A comprehensive characterization of corrosion products', Energy \& Fuels, 2014, 28, 6447-6458.

3. J. Lehmusto, B. -J. Skrifvars, P. Yrjas, M. Hupa: 'Comparison of potassium chloride and potassium carbonate with respect to their tendency to cause high temperature corrosion of stainless 304L steel', Fuel Processing Technology, 2013, 105, 98-105.

4. M. Montgomery, A. Karlsson: 'In-situ corrosion investigation at Masnedø CHP plant -a straw-fired power plant', Materials and Corrosion, 1999, 584, 579-584.

5. N. Israelsson, K. A. Unocic, K. Hellström, J. -E. Svensson, L. -G. Johansson: 'Cyclic corrosion and chlorination of an FeCrAl Alloy in the presence of KCl', Oxidation of Metals, 2015, 84, 269-290.

6. J. Lehmusto, P. Yrjas, M. Hupa: 'The effect of pretreatment on the corrosion resistance of superheater materials', Solid State Phenomena, 2015, 227, 309-312.

7. N. Israelsson, J. Engkvist, K. Hellström, M. Halversson, J. -E. Svensson, L. -G. Johansson: KCl-induced corrosion of an FeCrAl alloy at $600{ }^{\circ} \mathrm{C}$ in $\mathrm{O}_{2}+\mathrm{H}_{2} \mathrm{O}$ environment: The effect of preoxidation', Oxidation of Metals, 2015, 83, 29-53.

8. P. Viklund, R. Pettersson: HCl-induced high temperature corrosion of stainless steels in thermal cycling conditions and the effect of preoxidation', Oxidation of Metals, 2011, 76, 111-126.

9. M. Uusitalo, P. M. Vuoristo, T. Mäntylä: 'High temperature corrosion of coatings and boiler steels below chlorine-containing salt deposits', Corrosion Science, 2004, 46, 1311-1331. 
10. T. Hussain, T. Dudziak, N. J. Simms, J. R. Nicholls: 'Fireside corrosion behavior of HVOF and plasmasprayed coatings in advanced coal/biomass co-fired power plants', Journal of Thermal Spray Technology, 2013, 22, 797-807.

11. S. Kiamehr, K. V. Dahl, T. N. Lomholt, T. L. Christiansen, M. A. J. Somers: 'High temperature corrosion due to biomass firing: A study on the reactivity between potassium chloride and oxides. in International symposuim on High-temperature Oxidation and Corrosion, 2014, 144-147.

12. S. C. Okoro, M. Montgomery, F. J. Frandsen, K. Pantleon: 'High temperature corrosion during biomass firing: improved understanding by depth resolved characterisation of corrosion products', Materials at High Temperature, 2015, 32, 92-101.

\subsection{List of Figure Captions}

Figure 1. The surface morphology of oxides resulting from pre-oxidation of (a) Kanthal APM and (b) Nimonic $80 \mathrm{~A}$ at $900{ }^{\circ} \mathrm{C}$ for $168 \mathrm{~h}$.

Figure 2. Morphology and chemical composition of corrosion products formed on a pre-oxidized Kanthal APM sample after exposure to conditions mimicking biomass-firing.

Figure 3. Morphology and chemical composition of corrosion products formed on a virgin Kanthal APM sample after exposure to conditions mimicking biomass-firing.

Figure 4. Morphology and chemical composition of corrosion products formed on a pre-oxidized Nimonic 80A sample after exposure to conditions mimicking biomass-firing. The position of EDS acquisition is shown by the inserted box. 
Figure 5. Morphology and chemical composition of corrosion products formed on a virgin Nimonic 80A sample after exposure to conditions mimicking biomass-firing. The position of EDS acquisition is shown by the inserted box. 
9.0 Tables

Table1. Chemical composition of the investigated alloys.

\begin{tabular}{ccccccc}
\hline \multirow{2}{*}{ Alloy } & $\mathrm{Al}$ & $\mathrm{Ti}$ & $\mathrm{C}$ Cr & $\mathrm{Ni}$ & $\mathrm{Fe}$ & Others \\
\hline $\begin{array}{c}\text { Kanthal } \\
\text { APM }\end{array}$ & 5.9 & & 22.6 & & 70.9 & C, Si, Mn \\
$\begin{array}{c}\text { Nimonic } \\
\text { 80A }\end{array}$ & 1.3 & 2.2 & 20.6 & 75.0 & & $\begin{array}{c}\text { Zr, Cu, Co, } \\
\text { C, Mn, Si, } \\
\text { Co }\end{array}$ \\
\hline
\end{tabular}


Table 2. Gas composition employed to mimick biomass-firing conditions.

\begin{tabular}{cccccc}
\hline $\begin{array}{c}\mathrm{O}_{2} \\
(\text { vol \%, dry })\end{array}$ & $\begin{array}{c}\mathrm{CO}_{2} \\
(\text { vol \%, dry })\end{array}$ & $\begin{array}{c}\mathrm{H}_{2} \mathrm{O} \\
(\text { vol \%) }\end{array}$ & $\begin{array}{c}\mathrm{HCl} \\
(\text { ppmv, dry })\end{array}$ & $\begin{array}{c}\mathrm{SO}_{2} \\
\text { (ppmv, dry) }\end{array}$ & $\begin{array}{c}\mathrm{N}_{2} \\
\text { (vol \%, dry) }\end{array}$ \\
\hline 6 & 12 & 3 & 400 & 60 & 82 \\
\hline
\end{tabular}


10.0 List of keywords.

FeCrAl-alloy, superalloy, pre-oxidation, alumina, superheater, biomass, $\mathrm{KCl}, \mathrm{SO}_{2}, \mathrm{HCl}$, corrosion, chlorination, sulphation, SEM, EDS. 
Figures
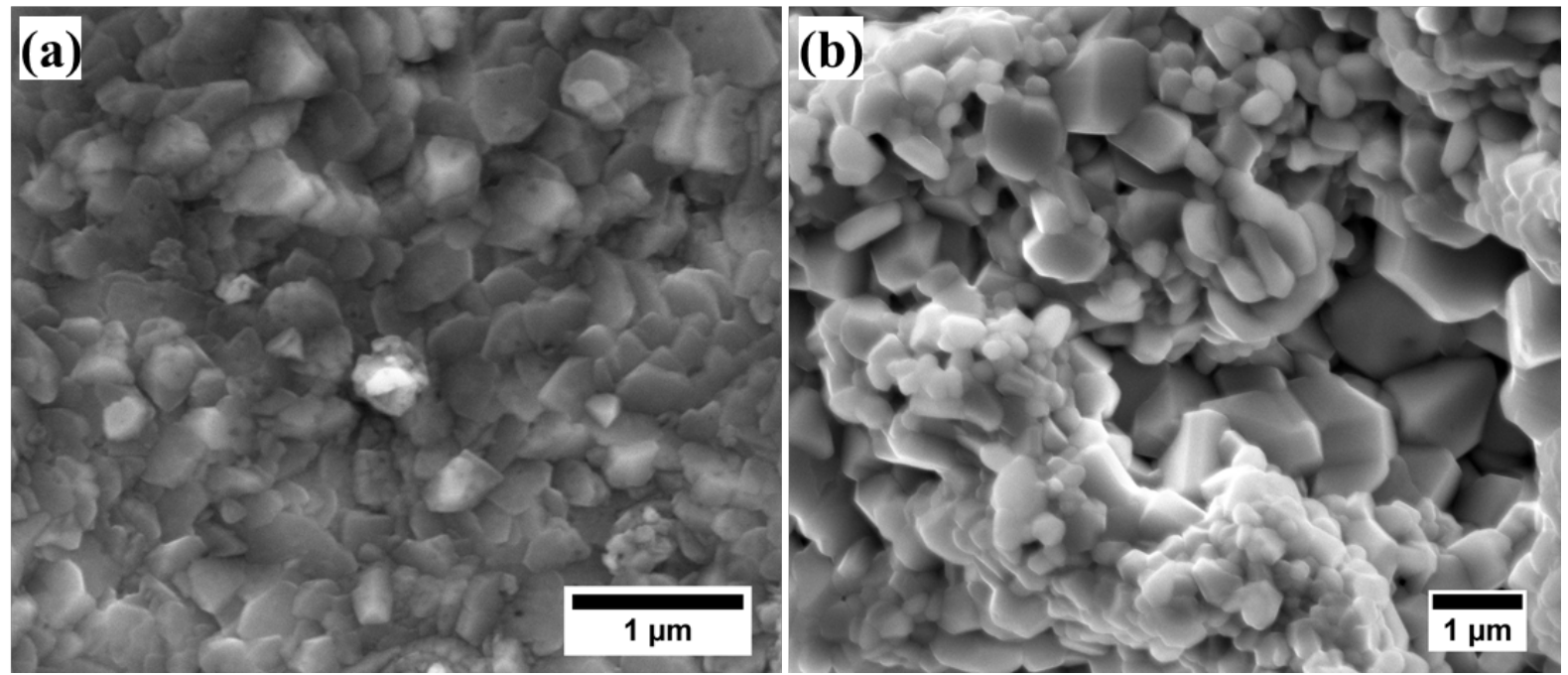

Figure 1.
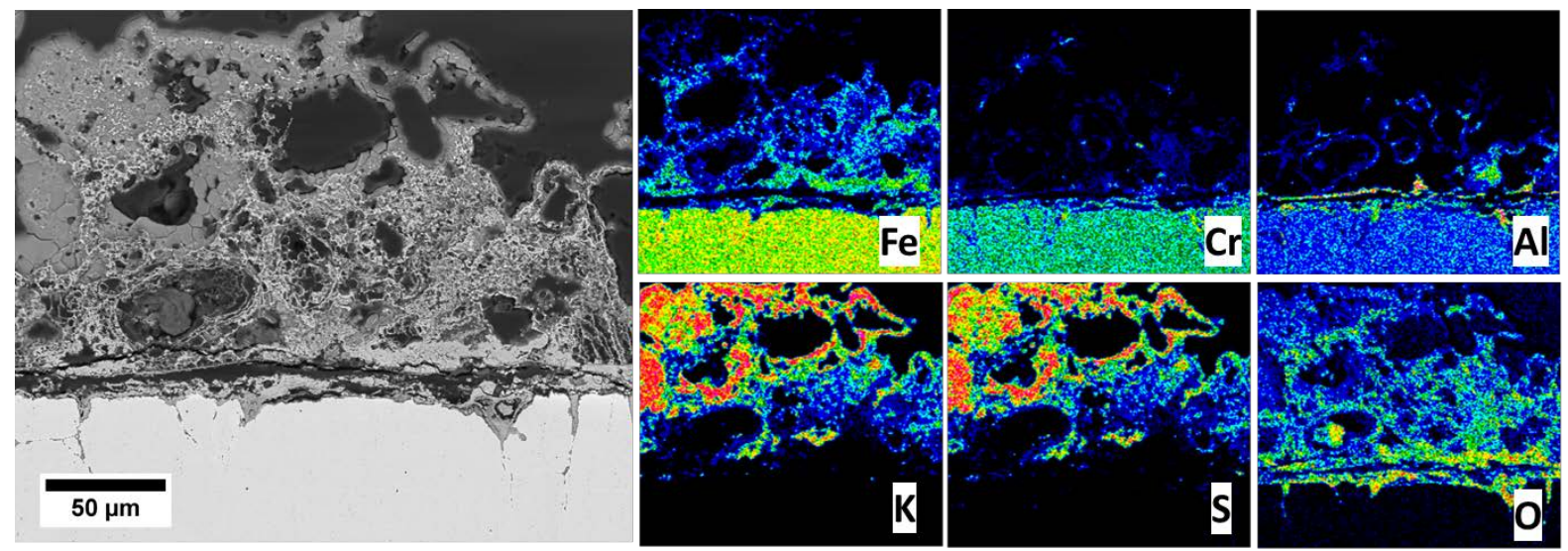

Figure 2. 

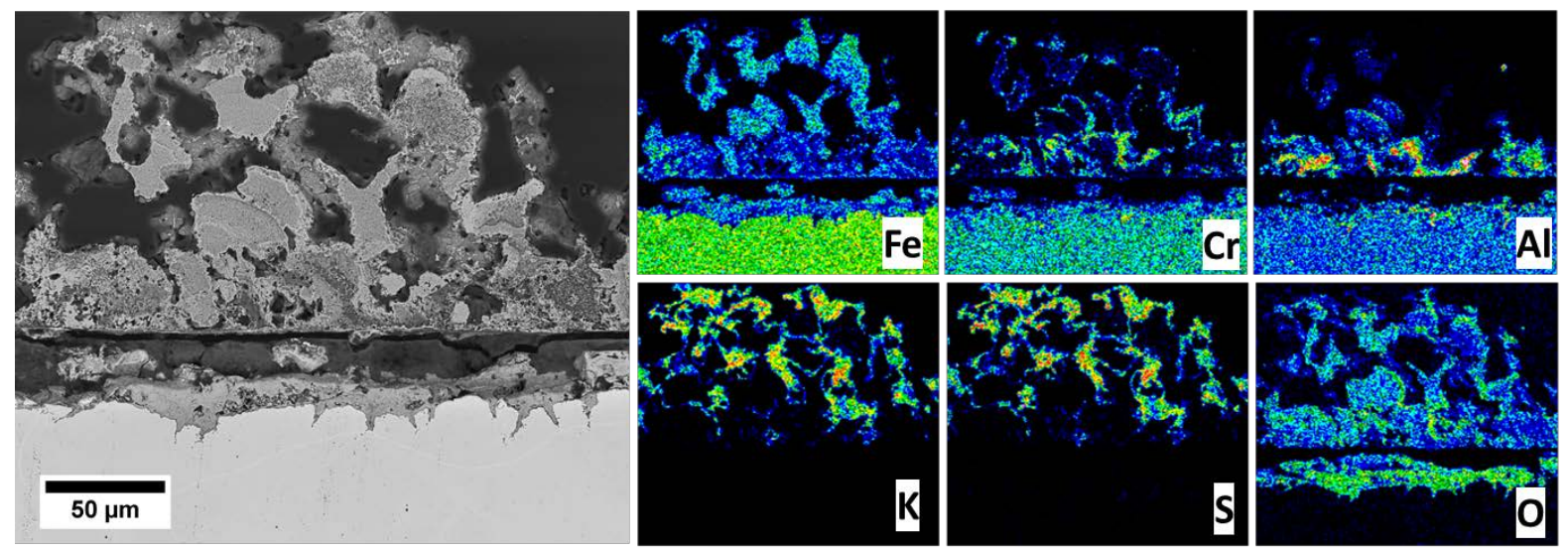

Figure 3.
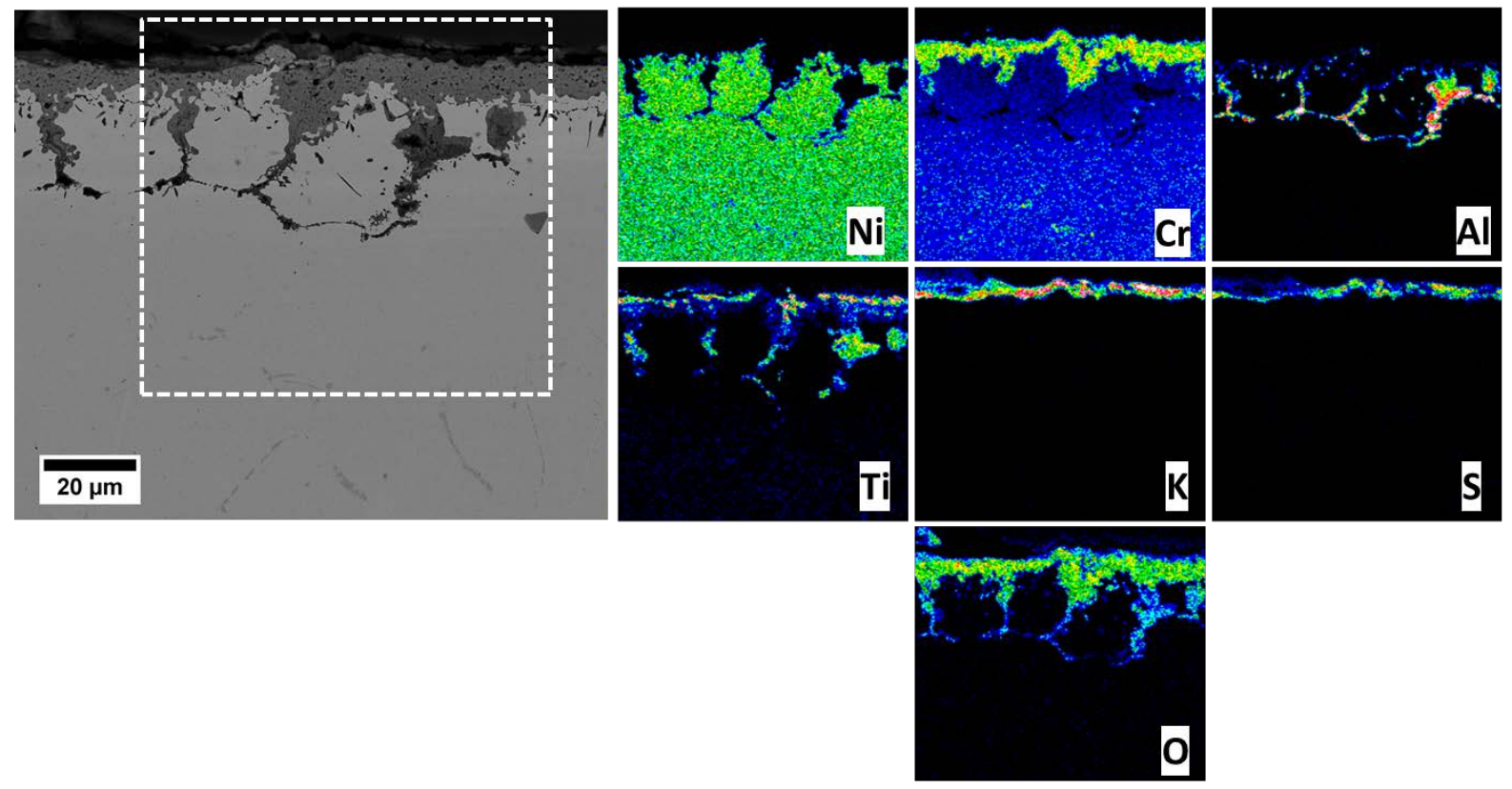

Figure 4. 


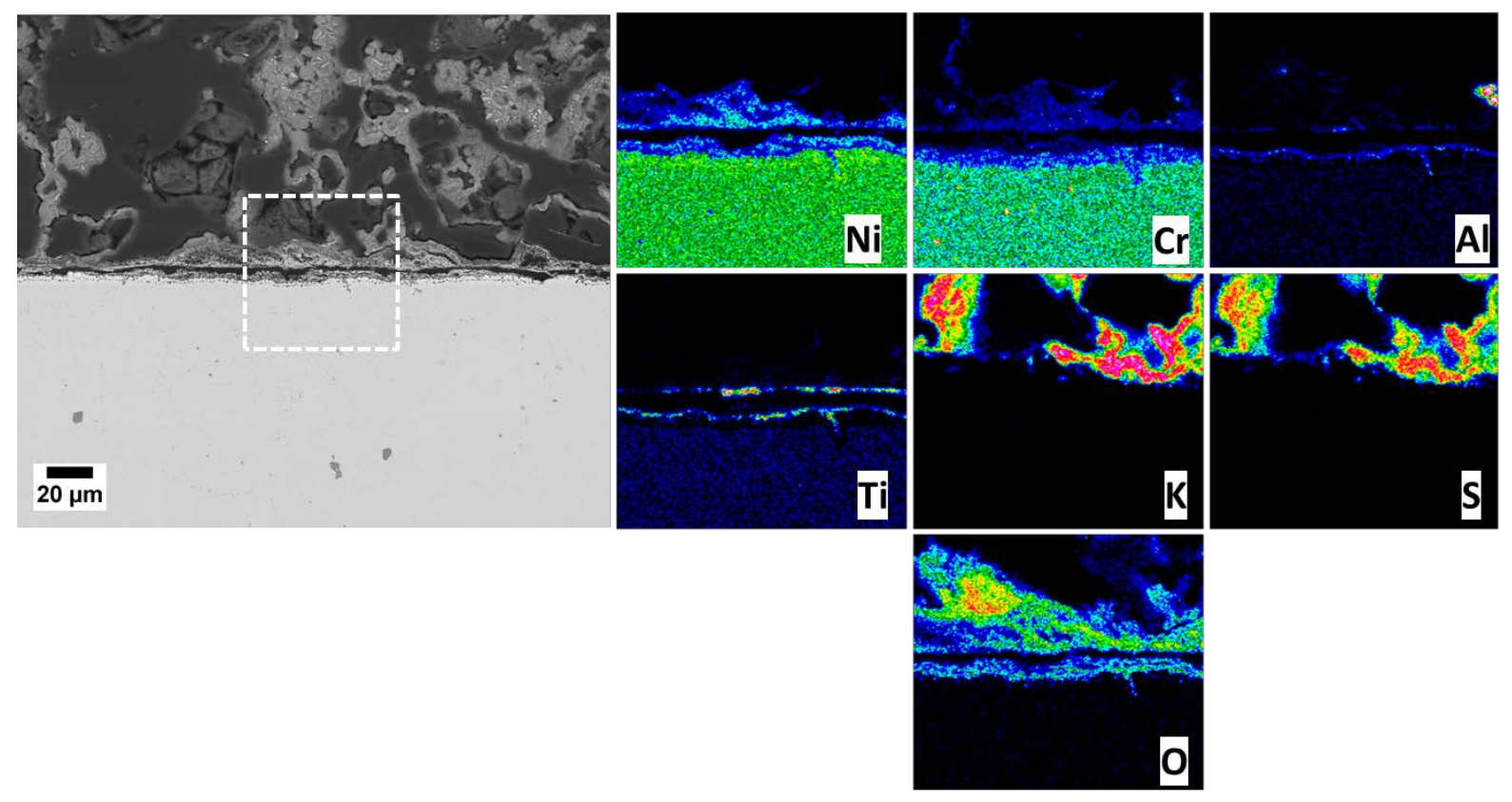

Figure 5. 